\title{
SELF-EVIDENCE
}

Carl Ginet*

\begin{abstract}
This paper develops an account of what it is for a proposition to be self-evident to someone, based on the idea that certain propositions are such that to fully understand them is to believe them. It argues that when a proposition $\mathrm{p}$ is self-evident to one, one has non-inferential a priori justification for believing that $\mathrm{p}$ and, a welcome feature, a justification that does not involve exercising any special sort of intuitive faculty; if, in addition, it is true that $\mathrm{p}$ and there exists no reason to believe that the proposition that $\mathrm{p}$ is incoherent, then one knows a priori that p. The paper argues that certain deeply contingent truths, e.g., the truth that I would now express by saying "I exist", can be self-evident to, and thus known a priori by, the person they are about at the time they are about; but, since they cannot be known a priori, or even expressed, by anyone else or at any other time, they should not count as a priori truths.

KEYWORDS - Self-evidence. Self-evident propositions. A priori truths, A priori knowledge. A priori justification.
\end{abstract}

RESUMO - Este estudo desenvolve uma abordagem do que significa para uma proposição ser autoevidente para alguém, baseado na ideia de que certas proposições são tais que plenamente entendê-las significa crer nelas. Argumenta-se que, quando uma proposição p é autoevidente para alguém, tem-se justificação a priori nãoinferencial para crer que p e, eis um traço bem-vindo, uma justificação que não envolve exercer qualquer tipo especial de faculdade intuitiva; se, em adição, é verdade que p e não existe nenhuma razão para crer que p é incoerente, então sabese a priori que $\mathrm{p}$. O estudo argumenta que certas proposições profundamente contingentes, por exemplo, a verdade que eu agora expressaria ao dizer "Eu existo", podem também ser autoevidentes para e, portanto, conhecidas a priori pela pessoa sobre a qual elas são, no momento sobre o qual elas são; mas, uma vez que elas não podem ser conhecidas a priori, ou mesmo expressas, por qualquer outro ou em qualquer outro momento, elas não deveriam contar como verdades a priori.

PALAVRAS-CHAVE - Autoevidência. Proposições autoevidentes. Verdades a priori. Conhecimento a priori. Justificação a priori.

The term "a priori" is widely used by philosophers but there is not much agreement about what it means. There is wide agreement that it primarily refers to a way of knowing that is in some sense independent

* PhD. in Philosophy. Professor of Philosophy at the Cornel University.

\begin{tabular}{|l|l|l|l|l|l|} 
VERITAS & Porto Alegre & v. 54 & n. 2 & maio/ago. 2009 & p. 9-31
\end{tabular}


of experience (though in what sense is not agreed) and that certain sorts of truths (e.g., elementary truths of arithmetic) are ones we typically know a priori and certain other sorts of truths (e.g., truths as to what the weather was like yesterday) are ones we do not and cannot know a priori. A derivative use of "a priori" is to specify a kind of truth, the kind which can be known a priori: a truth is a priori only if it is, or could be, known a priori. (Later I will raise a doubt as to whether that "only if" should be strengthened to "if and only if".) But beyond these points there is little agreement and I suspect that many who freely speak of the a priori have no well worked out view on the question of just what constitutes the a priori way of knowing.

I will try here to give an account of one basic sort of a priori knowing. It is a sort that I hope might serve as the foundation and key to a full account of the ways of knowing that should count as a priori, but that large (one might say grandiose) project I will not be able even to sketch here.

My account will assume without argument two things about knowing in general and one further thing about a priori knowing in particular. About knowing in general I will assume, first, that one can know only facts, i.e., that if one knows that $\mathrm{p}$ then it is true that $\mathrm{p}$; and second, that knowledge implies belief, i.e., that if one knows that $\mathrm{p}$ then one believes that $\mathrm{p}$. About a priori knowing in particular I will assume that what makes a case of knowing that $p$ a case of knowing a priori that $p$ is the way in which the subject's belief that $p$ is justified: to say that a piece of knowledge is a priori is to say that the belief involved is justified a priori.

Belief justifications in general, whether a priori or not, divide exhaustively and exclusively into two kinds, inferential and noninferential. In this paper I will try to explicate a non-inferential kind of a priori justification. The key notion in my explication will be self-evidence. I aim for an account such that if it is self-evident to a person that $p$ then that person has a priori and non-inferential justification for believing that $\mathrm{p}$; and if it is also true that $p$ then normally they know that $p$ and its being self-evident to them will be their way of knowing that $\mathrm{p}$. And I want an account on which its being self-evident to a person that $\mathrm{p}$ will not be a matter of their exercising any special sort of intuitive faculty. Later I will say something about why I take this to be an important desideratum.

\section{The account of self-evidence}

I believe I can give an account that has these desirable qualities by exploiting the idea (to put it in a simple preliminary way) that some propositions are such that fully understanding them requires believing 
them. Believing them is at least part of what it is to fully understand them, because they state a condition such that belief that the condition holds is constitutive of fully understanding the proposition. ${ }^{1}$

I shall first present two definitions, one of what it is for a proposition to be self-evident (period) and the other of what it is for a proposition to be self-evident to a particular person. Then I will go on to argue that when a person believes a proposition that is self-evident to them then they are justified in believing it. Here is a preliminary version of the first definition, preliminary because it will need a qualification, to be explained later (in this definition and hereafter I will use the phrase "what the sentence $\mathbf{p}$ says" as short for the phrase "what is said by one who utters $\mathbf{p}$ in normal circumstances in order to assert that p"):

(D1-prelim) For any declarative sentence $\mathbf{p}$ whose meaning is such that what the sentence $\mathbf{p}$ says does not vary from one context of utterance to another,

it is self-evident that $\mathrm{p}$ if and only if: the sentence $\mathbf{p}$ is such that, for any person $\mathbf{S}$, if $\mathbf{S}$ understands what the sentence $\mathbf{p}$ says then it follows that $\mathrm{S}$ believes what it says, namely, that $\mathrm{p}^{2}$

(Note that the restriction that what the sentence says does not vary from one context to another means that this definition does not apply to any sentence containing indexical terms, such as the sentence "I exist". Later I will consider whether (and how) what such a sentence says can be said to be self-evident to its utterer.)

\section{Relativity to sentences}

The definiens of (D1-prelim) speaks of what the sentence $\mathbf{p}$ says, rather than the proposition that $p$, mainly because the former is what I mean by talk of the proposition that $p$ and I might as well say what I mean. Also, I find it easier to know what I'm talking about when I talk about understanding what the sentence $\mathbf{p}$ says than when I talk about understanding the proposition that $\mathrm{p}$. Understanding what the sentence $\mathbf{p}$ says can be explained in terms of understanding the parts and the structure of the sentence; there is no comparably clear and

1 This idea is, of course, not new. In Quine \& Ullian 1970 statements are said to be self-evident just in case "to understand them is to believe them". Peacocke 1993 and Peacocke 1998 use the notion of a belief's being constitutive of the possession of a concept in giving an account of a priori truth; understanding a proposition requires, of course, understanding the concepts involved in it.

2 I use the plaintext letters " $p$ " and " $q$ " as variables ranging over sentences and the boldface versions as variables ranging over names of sentences. Thus a value for an occurrence of " $p$ " would be a sentence and a value for an occurrence of "p" would be a sentence in quotes. 
unproblematic way of explaining what is involved in understanding the proposition that $\mathrm{p}$.

But speaking of understanding what a sentence says, rather than of understanding a proposition, makes the object of understanding relative to sentences. It makes the particular sentence mentioned a part of what is understood (viz., what that sentence says). For it may be that someone understands what sentence $\mathbf{p}$ says but not what a different sentence q says, even though what $\mathbf{p}$ says is the same as what q says, i.e., they express the same proposition.

This relativizing of understanding to sentences might be thought to introduce a problem for our definition of self-evidence. If there are sentences $\mathbf{p}$ and $\mathbf{q}$ that say the same thing but are such that $\mathbf{p}$ satisfies the definiens of (D1-prelim) but q does not, then our definition would force us to say that what $\mathbf{p}$ says is self-evident but what $\mathbf{q}$ says is not self-evident, even though what $\mathbf{p}$ says is the same as what $\mathbf{q}$ says - a violation of Leibniz's law. ${ }^{3}$

But is there any pair of sentences that fills this bill? The most plausible sort of candidate I know of ${ }^{4}$ can be illustrated as follows. Consider the sentence (in decimal notation):

(A) $10+10=20$

That seems a good candidate for being a sentence such that you could not count as understanding what it says if you didn't believe what it says. Now consider the following sentence in binary notation:

$$
1010+1010=10100
$$

It certainly seems possible that someone who understands binary notation well enough to understand what $(B)$ says might not yet see that what (B) says is true (especially if they were able to understand what

3 One might be tempted to think that there is a more conclusive argument than the one I give below for the conclusion that there cannot be sentences $\mathbf{p}$ and $\mathbf{q}$ that say the same thing and such that one satisfies (D1-prelim) and the other does not. This conclusion would follow from the lemma that there cannot be two sentences saying the same thing that are such that someone understands what the one says but not what the other says. And one might think that this lemma follows, by Leibniz's law, from the premises (1) S understands what $\mathbf{p}$ says and (2) what $\mathbf{p}$ says is identical with what q says. But it does not. Premise (1) does not provide an extensional context for the referring term "what p says", such that the truth-value of (1) must be preserved by substitution of any co-referring term. This is because (1) entails that (3) S knows some truth of the form "What $\mathbf{p}$ says is that $r$ ". And from (3) and (2) it clearly does not follow that (4) S knows a truth of the form "What q says is that $r$ ".

4 Suggested to me by Bob Stalnaker in conversation many years ago. 
(B) says without translating it into decimal notation, i.e., into (A)). If so, I would want to say that it is self-evident that (speaking in decimal notation) $10+10=20$, but it is not self-evident (speaking in binary notation) that $1010+1010=10100$.

What (B) says might, however, seem to be the very same thing as what (A) says. After all, "1010" in binary notation designates the same number as "10" designates in decimal notation, and "10100" in binary notation designates the same number as "20" designates in decimal notation. But, I hope to persuade you, what (A) says and what (B) says are not the same thing.

What does each of the sentences in question say? (A) is in decimal notation. If you know how to interpret decimal notation you know that, for any numeral in that notation, $\mathbf{d}_{\mathbf{n}} \mathbf{d}_{\mathbf{2}} \mathbf{d}_{1}$, the first digit on the right, $\mathbf{d}_{1}$, gives the number of ones $\left[\mathrm{d}_{1} \times 10^{\circ}\right]$, the second digit from the right, $\mathbf{d}_{2}$, the number of tens $\left[\mathrm{d}_{2} \times 10^{1}\right]$, the third digit, $\mathbf{d}_{3}$, the number of hundreds $\left[\mathrm{d}_{3} \times 10^{2}\right]$, and so on. ${ }^{5}$ So a decimal representation consisting of a single digit $\mathbf{d}_{1}$ is read as naming the number that is $d_{1} \times 1$, one of two digits $\mathbf{d}_{2} \mathbf{d}_{1}$ means $\left(\mathrm{d}_{2} \times 10\right)+\left(\mathrm{d}_{1} \times 1\right)$; one of three digits $\mathbf{d}_{3} \mathbf{d}_{2} \mathbf{d}_{\mathbf{1}}$ means $(\mathrm{d} 3 \times 100)+(\mathrm{d} 2 \times 10)+(\mathrm{d} 1 \times 1)$; and so on. So what sentence $(A)$ says to one who takes it to be in decimal notation and understands decimal notation is the following:

$\left(A^{*}\right) \quad$ One ten plus one ten equals two tens.

And that is surely self-evident, as self-evident as what is said by any sentence of the form "One X plus one X equals two Xs", as self-evident as that $1+1=2$.

Sentence (B) is in binary notation. If you know how to interpret binary notation you know that the first digit on the right, d1, gives the number of ones $\left[\mathrm{d} 1 \times 2^{0}\right]$, the second digit from the right, $d 2$, the number of twos [d2 $\times 2^{1}$ ], the third digit, $d 3$, the number of fours [d3 $\times 2^{2}$ ], the fourth digit, d4, the number of eights $\left[\mathrm{d} 4 \times 2^{3}\right]$, and so on. So a binary representation of a single digit d $\mathbf{1}$ is read as naming the number that is $\mathrm{d} 1 \times 1$; one of two digits d2d1 means $(\mathrm{d} 2 \times 2)+(\mathrm{d} 1 \times 1)$; one of three digits d3d2d1 means $(\mathrm{d} 3 \times 4)+(\mathrm{d} 2 \times 2)+(\mathrm{d} 1 \times 1)$; one of four digits $\mathbf{d 4 d} \mathbf{d} \mathbf{d} 2 \mathrm{~d} 1$ means $(\mathrm{d} 4 \times 8)+(\mathrm{d} 3 \times 4)+(\mathrm{d} 2 \times 2)+(\mathrm{d} 1 \times 1) ;$ and so on. So what sentence $(B)$ says to one who takes it to be in binary notation and understands binary notation is the following:

5 I use the boldface letters with subscripts " $\mathrm{d}_{1}$ ", " $\mathrm{d}_{2}$ ", etc. as variables ranging over the single-digit numerals " 0 ", ..., "9" - i.e., names of the numbers $0, \ldots, 9$ - and I use the plaintext versions as variables ranging over those numbers. 
$\left(B^{*}\right) \quad$ One eight plus one two, plus one eight plus one two, equals one sixteen plus one four.

In decimal notation it says that $(8+2)+(8+2)=16+4$. And that is not self-evident. A relative beginner at arithmetic could fail to see that what " $(8+2)+(8+2)=16+4$ " says is true, even though she fully understands what it says - as evidenced, say, by her knowing how to go about figuring out whether it is true.

But it's also pretty intuitive that what $\left(B^{*}\right)$ says is not what $\left(A^{*}\right)$ says. These arithmetical truths are clearly different truths. The arithmetical fact that $10+10=20$ is not the same as the fact that $(8+2)+(8+2)=16+4$, and both are different from, for example, the fact that $\left(2^{2}+2^{2}+2\right)+\left(2^{2}+2^{2}+2\right)=5^{2}-5-$ despite its being the case that " 10 ", " $8+2$ ", and " $2^{2}+2^{2}+2$ " all name the same number, as do " 20 ", " $16+4$ ", and " $52-5$ ". Someone might know the first fact while not yet knowing the second or third facts, or might know the first and second while not yet knowing the third.

It is indeed compatible with fully understanding what (A) and (B) say that one believe what $(A)$ says and not what $(B)$ says, but this is because they do not say the same thing. In general, if two sentences do say the same thing, then anyone who fully understands both sentences must see that they say the same thing. ${ }^{6}$ So pairs of sentences like (A) and (B) do not after all present a problem for definition (D1-prelim).

\section{Examples}

Here are some examples of sentences whose meaning in English is such that, according to (D1-prelim), what they would say is selfevident.

(1) (a) One plus one is two.

(b) If a man is taller than his twin sister, then she is shorter than he is.

(c) Any triangle has three internal angles.

(d) For any true or false propositions $\mathrm{p}$ and $\mathrm{q}$ : if it is true that $\mathrm{p} \leftrightarrow \mathrm{q}$ and true that $\mathrm{p}$, then it is true that $\mathrm{q}$.

(e) A rhombus is a Euclidean plane figure.

(f) A rhombus is a Euclidean plane figure with four equal sides whose opposite sides are parallel.

6 Obviously, in my view to individuate things sentences say, propositions, in such a way that they are identical if necessarily equivalent is not to individuate them finely enough. 
To say that what sentence (1)(a) ("One plus one is two") says is self-evident is, according to (D1-prelim), to say that the meaning of the sentence is such that if a person fully understands what it says (i.e., what an utterance of it would say) then it follows that they believe what it says, namely, that one plus one is two. The idea is, to put it contrapositively, that if a person hesitates to accept what "One plus one is two" says, is uncertain whether one plus one is two, then it follows that the person does not fully understand what that sentence says. Believing that one plus one is two is a necessary, constitutive condition of fully understanding what "One plus one is two" says.

By way of contrast, here are some sentences such that what they say is not self-evident:

(2) (a) Seventy four times twenty three is one thousand seven hundred and two.

(b) Most men with twin sisters are taller than they are.

(c) The sum of the internal angles of any triangle equals the sum of two right angles.

(d) For any true or false propositions $\mathrm{p}, \mathrm{q}$, and $\mathrm{r}$ : it is true that [p $\leftrightarrow(q \leftrightarrow r)] \leftrightarrow[(p \leftrightarrow q) \leftrightarrow r]$.

(e) Most rhombuses shown in most geometry textbooks are not square.

To say that what sentence (2)(c) ("The sum of the internal angles of any triangle equals the sum of two right angles") says is not self-evident is to say that it is possible for someone to fully understand what that sentence says and yet fail to accept what it says, be uncertain whether the sum of the internal angles of any triangle equals the sum of two right angles. That a person hesitates to accept what (2)(c) says does not entail that the person fails to fully understand what (2)(c) says.

\section{Full Understanding}

Here there might arise an objection, one that presses me to say more about what constitutes full understanding. Why shouldn't we take a person's failure to accept what (2)(c) says (that the sum of the internal angles of any triangle equals the sum of two right angles) as a failure to completely understand what it says? In particular, as a failure to completely understand what a triangle is? Doesn't coming to learn the truth of what (2)(c) says, by seeing a proof of it, make one's understanding of the essential nature of triangles more complete? And shouldn't someone who lacks this more complete understanding of what a triangle is be said to lack a full understanding of what is said by sentence (2)(c)? 
Analogously, this questioner might say, someone may have a partial understanding of what a rhombus is, enough to know that a rhombus is a Euclidean plane figure, but lack the full understanding that would entail believing what (1)(f) says (that a rhombus is a Euclidean plane figure with four equal sides whose opposite sides are parallel). If fully understanding what (1)(f) says entails believing it, why doesn't fully understanding what $(2)(c)$ says entail believing it? If I want to say (as I do) that fully understanding what (1)(f) says entails believing it but that fully understanding what (2)(c) says does not entail believing it, then I need to give a plausible account of fully understanding what a sentence says that will yield this discrimination between the two cases.

There is, of course, a sense in which one who knows the fact expressed by (2)(c), that the sum of the internal angles of any triangle equals the sum of two right angles, understands the nature of triangles better or more completely than one who does not know this fact. But it does not follow that the latter person cannot be one who fully understands what sentence (2)(c) says. For what is required to fully understand what that sentence says is just that (a) one grasps the concept expressed by each of its descriptive (contentful) terms - e.g., "triangle", "internal angles", "sum", "equals", "right angles", "two" - well enough to be able to tell with respect to any candidate case, given sufficient relevant information about it, whether the concept applies in that case - we can speak of this as having application-competence with respect to the term - and (b) one correctly perceives the grammar of the sentence, i.e., one understands the way the sentence is put together well enough to know how the meaning of each of its descriptive terms contributes to what the sentence says. And certainly one who is ignorant of the truth of what (2)(c) says may nevertheless satisfy these requirements with respect to (2)(c). He may have application competence with respect to every one of (2)(c)'s descriptive terms and grasp its grammar perfectly and yet fail to believe what it says.

In contrast, one who is uncertain whether to accept what (1)(f) says (that a rhombus is a Euclidean plane figure with four equal sides whose opposite sides are parallel) fails to have application-competence for the term "rhombus" (assuming that they have application-competence for the other descriptive terms in (1)(f)): there will be particular Euclidean plane figures such that they will be unable to tell whether those figures are rhombuses no matter how much relevant information they have about them (of a sort that can be acquired without already having the concept of a rhombus). They may have partial application competence for the term "rhombus", since application competence can come in degrees. They may know that "rhombus" denotes a Euclidean plane figure - i.e., that what sentence (1)(e) says is true - but nothing about what sort of plane figure, 
or they may know that it designates one with four sides but nothing more, or one with four equal sides but nothing more. If their application competence for "rhombus" falls short of full competence then their understanding of what (1)(f) says falls short of full understanding. ${ }^{7}$

Similarly for the other sentences in (1), e.g., (1)(c). One who does not believe what sentence (1)(c) says (that any triangle has three internal angles) must fail to fully understand what it says, i.e., must lack application-competence for one or more of its descriptive terms ("triangle", "three", "internal angles"), or fail to grasp fully the grammar of the sentence, or both. No other explanation for the failure to accept what the sentence says is possible.

(I should note that, though adequate for present purposes, my explanation of full understanding is incomplete. I have described application-competence for the descriptive terms in (1)(c), (1)(e), (1)(f), (2)(c), and (2)(f) - terms such as "triangle", "rhombus", "right angle", Euclidean plane figure", "three" - as requiring the ability to determine with respect to any candidate case, given sufficient relevant information about it, whether the term applies in that case. Such a requirement is apt for those terms and many others in mathematics and logic, but it will not be apt for many other descriptive terms - for example, terms that are vague ("bald", "red", "tall"), evaluative terms whose meaning makes their application essentially contestable ("expensive"), and terms denoting natural kinds about which there are necessary truths that are only empirically discoverable ("water", "elm", "tiger") - and it is not apt for proper names ("Hannah", "London"). For terms of these sorts it will be necessary to complicate in one way or another the specification of what is required for application competence and thus what is required for full understanding of sentences in which such terms occur. I will not try here to work out these complications. For a great many of the sentences containing such terms that say things that are self-evident, it will be clear that their doing so does not depend on what the right account of those complications is - such as, e.g., "A man with no hairs on his head is bald", "An expensive car is not a cheap car", "Water is wet", "Elms are not animals", "Provided that Sarah and Hannah exist, ${ }^{8}$

7 Partial application competence can come in different varieties with different sorts of terms. Consider color terms. A young child might happily apply the term "red" to that shade we call "fire-engine red" but hesitate or refuse to apply it to other, more orangeish or bluish, shades of red.

8 The shorter sentence without this proviso - "If Sarah was born earlier than Hannah was born, then Hannah was born later than Sarah was born" - might not be accepted as saying something true by one who fully understands it but is not sure that the names "Sarah" and "Hannah" both refer. 
if Sarah was born earlier than Hannah was born, then Hannah was born later than Sarah was born." 9 )

\section{A qualification}

I said above that for sentences like those in my list (1), if a person doubts what is said by one of them, no explanation of this is possible other than that they fail to fully understand what is said by the sentence. Actually, one other sort of explanation may sometimes be possible for some sentences such that what they say is self-evident. Clear illustrations of the recherché possibility I have in mind are hard to come by, but the following may suffice to explain the idea. Consider the sentence

For any property actually possessed by some entities, there is a set whose only members are all of the things that possess that property.

It's plausible to think that there was a time when a person's failure to believe what this sentence says would have been knockdown evidence that they lack application-competence for the term "set", that they fail to fully understand what a set is (assuming they have applicationcompetence for the other descriptive terms in the sentence and grasp the grammar of the sentence). (If this is not an actual historical truth, it represents a possible history.) Then came Russell's paradox: a deduction of a contradiction from what this sentence says and things said by other sentences that they took to be (and we still take to be) necessary truths (namely, that the property of being an entity that does not have the set-membership relation to itself is a genuine property [indeed, one possessed by some actual things] and that everything must either possess or lack that property). That proof gave people who fully understood what sentence (3) says reason to believe that what it says is incoherent - in the sense that its negation can be deduced from necessarily true premises - and thus reason to doubt, indeed deny, that what it says is so. And this gave them reason to think that the notion of a set, as hitherto

9 Proper names offer a plausible example for which the decision as to whether a sentence containing them says something self-evident does depend on the right account of application competence for that sort of term. Consider sentences of the form 'If a exists, then $a=a$ ' where $a$ is a proper name. If the convention in the language in which such a sentence occurs is that occurrences of the same name within the same sentence must refer to the same object (as in many formal languages), then what such a sentence says is self-evident. But if there is no such convention (as arguably there is not in English), then what it says is not selfevident. 
defined by the axioms of "naïve" set theory (as we now call it), was incoherent.

This example suggests that to our definition of self-evidence we need to add a disjunct to cover the sort of circumstance illustrated in the example. Although that sort of circumstance does not obtain, and is highly unlikely ever to obtain, with respect to what is said by any of the sentences in (1), it seems hard to deny that it is at least a metaphysical possibility that it should do so. Thus, if we want our definition of selfevidence to cover what is said by those sentences (as I do), we need to revise our definition by inserting a disjunct to cover this possibility.

Our revised definition can be stated as follows

(D1) For any declarative sentence $\mathbf{p}$ whose meaning is such that what the sentence $\mathbf{p}$ says does not vary from one context of utterance to another,

it is self-evident that $\mathrm{p}$ if and only if: anyone who fully understands what they would say by uttering the sentence $\mathbf{p}$ must either (i) believe what they would thereby say, namely, that p, or (ii) think they have reason to believe that what they would thereby say is incoherent.

\section{Self-evidence is noninferential a priori justification}

I am now in a position to present my second definition, of what it is for a proposition to be self-evident to someone:

(D2) For any declarative sentence $\mathbf{p}$ whose meaning is such that what the sentence $\mathbf{p}$ says does not vary from one context of utterance to another,

it is self-evident to $\mathrm{S}$ that $\mathrm{p}$ if and only if: it is self-evident that $\mathrm{p}, \mathrm{S}$ believes that $p$, and $S$ does not think she has reason to believe that what sentence p says is incoherent.

I claim that

(J) If it is self-evident to $\mathrm{S}$ that $\mathrm{p}$ then $\mathrm{S}$ is justified in believing that $\mathrm{p}$.

Consider again sentence (1)(c) ("Any triangle has three internal angles"). Someone who does not believe what that sentence says - who denies that what it says is true or is uncertain whether it is true - does not fully understand what that sentence says (provided that he does not think he has reason to believe that what the sentence says is incoherent). Someone who does fully understand what it says (where the just mentioned proviso holds), and therefore believes it, is, according to (J), justified in believing it.

How so? The fact which constitutes her being justified is simply the fact that she fully understands what the sentence says (and does 
not think she has reason to think it incoherent). This entails that she believes what it says. So it cannot be that she ought not to believe it even though she fully understands what it says (and does not think she has reason to think it incoherent). Nor can it be that she ought not to understand what it says (or that she ought to think she has reason to think it incoherent). If she cannot be rationally criticized for fully understanding it (or for not thinking she has reason to think it incoherent), then she cannot be criticized for what these things entail, her believing it. Therefore, given that she fully understands what it says (and does not think she has reason to think it incoherent), she is justified in believing it.

The fact that she fully understands it (and does not think she has reason to think it incoherent) is her justification, but this fact clearly does not constitute an inferential justification: it involves no belief in any premise such that she believes that what the sentence says is legitimately inferable from that premise. If what a sentence says is self-evident to a subject, then the subject's belief in it is non-inferentially justified.

And this sort of justification is clearly a priori (if any is). It certainly satisfies any plausible negative constraint on a priori justification: it is not justification by sense perception or by introspection; nor is it by inference ultimately from perceptual or introspective beliefs. Indeed, the only experience that justification by self-evidence requires of its subject is whatever was needed in order to fully understand what the sentence in question says, and that is no reason to deny that the justification is a priori.

An important merit of justification by self-evidence, as I have explained it, is that it involves no appeal to any special way of coming to believe what the sentence says - by clear and distinct perception, or rational intuition, or the like. It involves just fully understanding what the sentence says (and not thinking one has reason to think it incoherent) and therefore believing it. The justificatory force does not arise from any special justificatory quality attaching to the understanding or to the believing or to some accompanying mental state. It arises just from the fact that for these special sentences fully understanding what one of them says (while not thinking one has reason to think it incoherent) entails believing it. This is important because our account of justification by self-evidence, in being free of appeal to any special sort of mental state or process, is free of any of the difficulties or disputes that are apt to arise about the nature of such special states and about their credentials as justifiers. The account avoids having to face the question of what defines such a special state or process and the question of how its nature justifies one in believing its deliverances. 


\section{Does belief entail full understanding?}

So in certain sorts of cases fully understanding (while not thinking one has reason to think incoherent) entails believing. Is there also an entailment the other way, from believing to fully understanding? Consider sentence (1)(e), "A rhombus is a Euclidean plane figure". Must someone who believes what that sentence says, believes that a rhombus is a Euclidean plane figure, fully understand what it says? Well, no, it is not necessary that they fully understand that (or any other) English sentence. A monolingual speaker of Japanese can believe that a rhombus is a Euclidean plane figure. The question I really want to ask is this: If someone says, "I believe that a rhombus is a Euclidean plane figure" and he speaks the truth, does it follow that he fully understands what the sentence "A rhombus is a Euclidean plane figure" says?

Suppose S knows that the term "rhombus" designates a kind of Euclidean plane figure but does not know that a rhombus is a Euclidean plane figure with four equal sides whose opposite sides are parallel; $\mathrm{S}$ lacks application-competence for the term "rhombus" and so does not fully understand what is said by the sentence "A rhombus is a Euclidean plane figure". And suppose that S lacks application-competence for any synonymous term, in English or any other language; i.e., S does not fully understand any sentence that says that a rhombus is a Euclidean plane figure. Does it follow that, although $\mathrm{S}$ can believe that the word "rhombus" designates a kind of Euclidean plane figure, S cannot believe that a rhombus is a Euclidean plane figure?

It is clear that at least some understanding of what a sentence says (or of what some same-saying sentence says), and more than a tiny bit, is necessary for being in a position to believe what it says. I find in a textbook on topology (Kelley, 1955, p. 146) after the word "THEOREM" the following sentence:

If $\mathrm{X}$ is a locally compact topological space which is either Hausdorff or regular, then the family of closed compact neighborhoods of each point is a base for its neighborhood system.

I am quite confident, and with plenty of justification, that what the author says with that sentence is true. But if I were to say, "I believe that if $\mathrm{X}$ is a locally compact topological space ... etc.", I would thereby pretend to a much greater comprehension of the concepts of topology than I in fact possess.

Suppose S knows very little English. S has learned that the word "rhombus" designates some sub-kind of the kind of thing that "Euclidean plane figure" designates, but doesn't know what kind either term designates, doesn't have application-competence for either term. It would surely be 
misleading for S to say, "I know (believe) that a rhombus is a Euclidean plane figure." $\mathrm{S}$ would imply that he understands what the sentence "A rhombus is a Euclidean plane figure" says more fully than he does.

How well does someone have to understand what a sentence says in order to be in a position to believe what it says? If we don't require full understanding and don't allow scant understanding, where in between shall we draw the line? I am unable to see any way of specifying a kind or degree of understanding other than full understanding that would clearly be enough for believing. And I'm inclined to think that, if we lack any principled and motivated way of drawing a line somewhere between scant and full understanding, then it would be arbitrary to draw it anywhere short of full understanding. Therefore, it should be drawn at full understanding. We should rule that a person cannot correctly say of herself "I believe that $p$ " if she does not fully understand what $\mathbf{p}$ says.

We should, however, allow that a person who does not fully understand what $\mathbf{p}$ says might convey a truth about herself by falsely saying "I believe that p". She may convey at least that she believes that what the sentence $\mathbf{p}$ says is true. And she may convey something more, about what she takes the relation(s) among the meanings of the words in the sentence to be. Someone who doesn't know that a rhombus is a Euclidean plane figure with four equal sides whose opposite sides are parallel may say "I believe that a rhombus is a Euclidean plane figure" and mean that she believes that the word "rhombus" designates a kind of Euclidean plane figure. (Such a person, though failing to satisfy our criterion for full understanding of the sentence "A rhombus is a Euclidean plane figure", because she lacks application-competence for "rhombus", may nevertheless fully understand the sentence "The word 'rhombus' designates a kind of Euclidean plane figure.")

If we have it that S's believing what $\mathbf{p}$ says entails S's fully understanding what $\mathbf{p}$ says, we can affirm the following: In a case where what $p$ says is self-evident, $\mathbf{S}$ 's believing what $\mathbf{p}$ says (while not thinking she has reason to believe it is incoherent) entails S's being justified in believing it. If $\mathbf{S}$ believes what $\mathbf{p}$ says then $\mathbf{S}$ fully understands what $\mathbf{p}$ (or some same-saying sentence) says; and if what $\mathbf{p}$ says is self-evident (and S does not think she has reason to think it is incoherent), then by the argument given earlier, S's belief that $\mathrm{p}$ is justified.

\section{Self-evidence and knowledge}

If S's belief that $\mathrm{p}$ is true, as well as justified in this way by selfevidence, does it follow that $\mathrm{S}$ knows that $\mathrm{p}$ ? Suppose that, although the proposition that $\mathrm{p}$ is an elementary truth of logic or mathematics, it has recently become widely (but mistakenly) believed by experts 
that the proposition that $\mathrm{p}$ is incoherent, but this fact is unknown to $\mathrm{S}$, a non-expert. Such a fact would, it seems to me, require us to judge that $\mathrm{S}$ does not know that $\mathrm{p}$, despite having a true belief that $\mathrm{p}$ justified by self-evidence. It would be nice to be able to illustrate this intuition with a sentence $\mathbf{p}$ such that we'd be prepared to grant that (a) it is true that $p,(b)$ there is someone to whom it is self-evident that $p$, but (c) it is believed by experts that the proposition that $\mathrm{p}$ is incoherent. But I can think of no such sentence.

My earlier example of sentence (3) ("For any property actually possessed by some entities, there is a set whose only members are all of the things that possess that property.") is not one about which we are prepared to grant that what it says is true. However, perhaps it can nevertheless be used to construct a fictional example that might be usable as an illustration. Suppose that eventually some, but not all, settheory experts come to think that what (3) says is true (that the best way to develop set-theory, after all, is to take that proposition as an axiom and reject some other premise involved in Russell's paradox). To them, however, what (3) says, though true, will not be self-evident, for they are still aware of some reason to think that what sentence (3) says is incoherent - namely the fact that Russell's paradox is still held by some experts to be a sound proof - even though they now have what they take to be better reason to think that Russell's proof is not sound and that what sentence (3) says is not after all incoherent. Suppose now that they consider Schmege, a logician of the late nineteenth-century before the discovery of Russell's paradox, to whom what (3) says was self-evident. Should they not judge that, although Schmege's belief in what (3) says was justified and true, it was not knowledge - precisely because, though Schmege did not realize it, a contradiction can be deduced from what (3) says and other propositions that were also self-evident to Schmege? I think they should.

If this is right, then S's having a true belief that $\mathrm{p}$ justified by selfevidence is not sufficient for S's knowing that $\mathrm{p}$. It must also be the case that there does not exist reason to believe that the proposition that $p$ is incoherent. The relation between self-evidence and knowledge is then as follows: if it is true that $\mathrm{p}$, it is self-evident to $\mathrm{S}$ that $\mathrm{p}$, and there does not exist reason to believe that the proposition that $p$ is incoherent, then $\mathrm{S}$ knows that $\mathrm{p}$. This is an a priori way of knowing that $\mathrm{p}$, because the justification involved, self-evidence, is a priori. So we can affirm the following:

(K) S knows a priori that $\mathrm{p}$ if: it is true that $\mathrm{p}$, it is self-evident to $\mathrm{S}$ that $\mathrm{p}$, and there does not exist reason to believe that the proposition that $p$ is incoherent. 
Could there be any reason to doubt this claim? There are those who deny that a priori knowledge is possible. ${ }^{10} \mathrm{How}$ are they likely to react to claim K? It would not, I think, be plausible to deny that if someone satisfied the condition laid down in $\mathrm{K}$ then they would know a priori that $\mathrm{p}$. Deniers of a priori knowledge would, I think, instead claim that this condition cannot be satisfied, specifically, that no sentence does, or can, satisfy our definition of what it is for something to be self-evident to S (D2) because none can satisfy our definition of self-evidence (D1). But could any case be made for this? I claim that the sentences in list (1) above satisfy (D1), that if someone fully understands one of those sentences (while not thinking she has reason to believe that what it says is incoherent), then it follows that she believes what it says. It's hard to see what could show this to be wrong. It is hard to see how there could, for example, be a clear case of someone who is reluctant to believe what is said by the sentence "One plus one is two", is utterly without any idea that what it says may be incoherent, but nevertheless fully understands what the sentence says. ${ }^{11}$ Until we are given reason to think that there are, or could be, cases of that sort for sentences like those in list (1), it is reasonable to hold that these sentences (and many others) do satisfy our definition of self-evidence, and that what such sentences say can therefore be known a priori.

\section{The contingent self-evident}

Are there any sentences such that what they say is both self-evident and only contingently true (if true at all)? Consider any sentence of the following form:

(4) If in the actual world there is exactly one thing that is a $G$, then the actual $G$ is a $G$.

What such a sentence says is self-evident: failure to believe what it says would betray failure to fully understand what it says. Anyone who fully understands this conditional sentence (and such a person must

${ }_{10}$ For example: Harman 2003, Devitt 1998, Devitt 2005.

11 Goldman 1979 (p. 4) rhetorically asks, with respect to any simple logical truth, "Can't we conceive of psychological operations that would suffice to grasp the components and ... [composition] of ... [the proposition] but do not suffice to produce belief in the proposition?" Assuming that grasping the components and composition of a proposition entails fully understanding it, I myself cannot conceive of such operations for any proposition expressed by one of the sentences in my list (1), that is, I cannot imagine anything I would be willing to count as satisfying Goldman's description with respect to it.

${ }^{12}$ Kitcher 1980 suggests that sentences like these express contingent a priori propositions. 
have mastered some technical terms in the philosophy of language) understands that if its antecedent is true then its consequent is true. But if its antecedent is only contingently true - it is only contingently true that in the actual world there is exactly one thing that is G (for example, let "G" be "person named Carl Ginet born in 1932 who became a philosopher") what the whole conditional sentence says is also only contingently true. It is true in the actual world but not in any other possible world where the thing that is $\mathrm{G}$ in the actual world exists but is not $\mathrm{G}$ (where I exist but am not named Carl Ginet or do not become a philosopher). For in such a world the consequent is false (it is not the case that the actual $G$ is $G$ there) but the antecedent is still true (it is still the case that in the actual world exactly one thing is $\mathrm{G}$ ).

What a sentence of form (4) says is a peculiarly uninformative sort of contingent truth. For it gives us no information that distinguishes the actual world from any other world: it is, as Gareth Evans has put it, ${ }^{13}$ only superficially contingent and not deeply contingent.

The superficiality of the contingency of what such a sentence says can be seen as follows. What it implies about any arbitrarily selected world w can be put this way:

(4a) It is true at the actual world that $\exists \operatorname{lxG}(\mathrm{x}) \rightarrow$ it is true at world $\mathrm{w}$ that $G$ (the actual $G$ ).

This fails to hold for a world w where the actual $G$ is not G. What (4) implies about the actual world, namely,

(4b) It is true at the actual world that $\exists ! x G(x) \rightarrow$ it is true at the actual world that $\mathrm{G}$ (the actual $\mathrm{G}$ ).

does hold because what (4b) says is formally true. And from a formal truth about the actual world we can learn nothing that distinguishes it from any other possible world. (4) is contingent because there are possible worlds where what (4) says would be false; but it is not deeply contingent because what (4) tells us about the actual world does not distinguish it from any other possible world.

Are there any sentences such that what they say is deeply contingent and also self-evident? I can think of none that, like (4), fits (D1), the definition of self-evidence given earlier. But consider the sentence

(5) I exist.

Because (5) contains the indexical term "I", whose meaning is such that its referent changes depending on who utters it, definition (D1) does

${ }^{13}$ See Evans 1979, from which I have derived my understanding of this distinction. 
not apply to this sentence. But it is clear that one cannot understand what the sentence "I exist" says and not believe what it says. It certainly seems that the essence of my notion of self-evidence is present here.

If so, what definition of self-evidence for context-sensitive sentences will capture it properly? For a time I thought the following definition would do the trick:

(D3-prelim) For any declarative sentence $\mathbf{p}$ whose meaning is such that what it says may vary from one context of utterance to another,

if a person $\mathrm{S}$ utters $\mathbf{p}$ in order to make an assertion and understands and believes what she thereby says, then what $\mathbf{S}$ thereby says is self-evident to $\mathrm{S}=$ def

for any person $\mathrm{x}$, if $\mathbf{x}$ were to utter $\mathbf{p}$ in order to make an assertion and fully understood what she would thereby say, then it follows that $x$ would believe what $x$ would thereby say (assuming $x$ does not have reason to think that what she would thereby say is incoherent).

What this definition gives us is no doubt a plausible way of using "self-evident" with respect to context-sensitive sentences. But it turns out that it is not the way I want (as Pryor 2006 has helped me to see).

What I want is a definition on the basis of which it will be plausible to claim that when what would be said by someone's uttering a contextsensitive sentence is self-evident to that person, she has a priori (as well as non-inferential) justification for believing what would be said. But there are context-sensitive sentences that satisfy (D3-prelim) of which it would not be plausible (or at any rate I would not want) to claim that an utterer's justification for believing what she says is a priori.

Consider this sentence:

I am uttering a sentence.

About this sentence Pryor (2006) says:

Given what this sentence means, it follows that whenever it's used to think a thought, that thought is true. (I count rehearsing a sentence to yourself privately as a kind of utterance.) And anyone who understands the sentence is in a position to know this. However, suppose you do utter the sentence (either privately or aloud). What then justifies you in believing that you are uttering it, or any sentence? It can't be your understanding of the sentence. That would only justify you in having beliefs about what's true whenever the sentence is uttered. It doesn't help you determine when that condition is fulfilled. The natural thing to say is that what justifies you in believing you are uttering the sentence is your introspective or perceptual awareness of uttering it. Hence, your justification for believing the thought you have by rehearsing (8) is a posteriori - despite the fact that you know, just by virtue of understanding (8), that whenever it's used to think a thought, that thought is true. [Underlining added.] 
If a person utters (6) in order to make an assertion and understands what she thereby says, it follows that she believes what she thereby says; so this sentence satisfies (D3-prelim). (But couldn't she fail to believe what it says because she fails to be aware that she has uttered it? She could, but in that case it could not be that she uttered it in order to make an assertion: one cannot utter something while intending by that act to make an assertion without being aware of one's act.)

The awkward thing is that, as Pryor says, at least part of what justifies the utterer in believing what she says in uttering "I am uttering a sentence" is her awareness that she is uttering it. (And there are other sentences that satisfy (D3-prelim) of which a similar thing is true, e.g., "I am uttering English", "I am uttering a sentence about what I'm currently doing.") I agree with Pryor that if awareness that one's experience is currently of some particular sort is essential to one's being justified in a belief then one is not justified a priori: one's justification is not independent of experience in the way required for it to be a priori. Since (D3-prelim) makes what is said in uttering these sentences selfevident to the utterer, it is not a definition of self-evidence for contextsensitive sentences that yields the result that, whenever what is said by the utterance of a context-sensitive sentence is self-evident to its utterer, that person is justified a priori in believing what they've said: it is not the definition of self-evidence for such sentences that I want.

What is the definition I want? I believe it is the following:

(D3) For any declarative sentence $\mathbf{p}$ whose meaning is such that what it says may vary from one context of utterance to another,

if at any given time a person $\mathrm{S}$ understands and believes what she would say were she then to utter $\mathbf{p}$ in order to make an assertion (whether or not $\mathbf{S}$ then actually utters $\mathbf{p}$ ), then what $\mathbf{S}$ believes is self-evident to $\mathbf{S}=\operatorname{def}$ for any person $\mathrm{x}$, if $\mathrm{x}$ understands what she would say were she to utter $\mathbf{p}$ to make an assertion then it follows that $\mathrm{x}$ believes what she would thereby say (assuming $x$ does not have reason to think that what she would thereby say is incoherent).

This is not satisfied by sentence (6) (or by "I am uttering English" or "I am uttering a sentence about what I'm currently doing"). One can understand what one would say by uttering that sentence at a time when one is neither uttering it nor in any other way occurrently thinking the thought that it expresses. At such a time one will not (normally) believe what one would say by uttering it (namely, that one is uttering a sentence).

Contrast sentence (5) "I exist". There cannot be a time at which one understands that sentence and fails to believe what one would say by uttering it (or it fails to be true). Every time at which one understands 
it must be a time at which one believes it. This includes times at which one is neither uttering that sentence nor in any other way occurrently thinking the thought that it expresses. The same is true of some other sentences, such as "I am" or "The world contains me".

But there are still others of which it is not true, such as "I am thinking" or "I am conscious". "I am thinking" implies that one is in a particular state such that it is possible to exist without being in that state. At a time when one exists but is not thinking one might understand "I am thinking" but not believe what it says. On the other hand, if one is thinking and one understands "I am thinking", then one will of course believe that one is thinking and be justified in doing so; but one's being justified does not follow merely from the fact that one understands what one would say by saying "I am thinking"; it's required also that one be aware that one's current state is of the thinking kind. Since one's justification is in this way dependent on one's having a particular kind of experience, it should be regarded as a posteriori.

But in the case of "I exist" or "I am" or "The world contains me" or any sentence such that what one says by uttering it is self-evident to one in the sense of (D-3), one's being justified in believing what one says does follow merely from one's understanding it. It is not also required that one be aware that one's condition is of some particular kind that it might not have been, for none of those sentences implies that one's condition is of any particular kind. Since one's justification is not dependent on one's being aware of being in any particular condition, one's justification should be regarded as a priori, not a posteriori.

Although what a person would say by uttering "I exist" is self-evident to the utterer (in the sense of (D-3)), and hence known a priori by them, it is also contingent. And it is deeply contingent. For in knowing at a particular time that I exist I know something that distinguishes the actual world from some other possible worlds, namely, those where I do not exist at that time. What my utterance of (5) "I exist" would say about any arbitrarily selected world w, namely,

It is true at world $w$ that $\exists x x=m e$

fails to hold for any world w where I do not exist. What my utterance of (5) would say about the actual world, namely,

(5b) It is true at the actual world that $\exists \mathrm{xx}=\mathrm{me}$

is true, of course, but, unlike (4b), it is not formally true. So we do not have the sort of reason we had with respect to (4b) for saying that we learn nothing from its truth that distinguishes the actual world from any other possible world. Nor do I see that we have any other sort of reason for 
saying so. So what I would say in uttering "I exist" is deeply contingent, as well as something I know a priori.

\section{A priori truth}

Philosophers speak of a priori truth as well as a priori knowledge. We've used our notion of self-evidence to define a species of a priori knowledge. Can we use it to define a species of a priori truth? One plausible thought as to the general relation between a priori knowledge and a priori truth is that a truth is a priori just in case it is, or can be, known a priori. This might suggest that we should say that if a truth is, or could be, self-evident to someone, then it is a priori. Or, more precisely, the suggestion is that we should say the following: if a sentence $\mathbf{p}$ is such that were $\mathbf{S}$ to utter $\mathbf{p}$ in order to make an assertion then $\mathrm{S}$ would assert a truth that is self-evident to $\mathrm{S}$, then the truth $\mathrm{S}$ would have expressed by uttering $\mathbf{p}$ is a priori.

There can be no objection to this suggestion as long as we consider sentences that satisfy definition (D1), sentences such that what they say cannot vary from one context of utterance to another - like those in list (1) or sentences of form (4) (like "If in the actual world there is exactly one person named Carl Ginet who was born in 1932 and became a philosopher, then the actual person named Carl Ginet who was born in 1932 and became a philosopher became a philosopher").

But some sentences which are such that what they say does vary from one context of utterance to another - sentences to which definition (D3), but not (D1), applies - should, I think, give us pause. In particular there seems reason to doubt that a sentence which would when uttered by $\mathrm{S}$ express a truth self-evident to $\mathrm{S}$ that is deeply contingent - a sentence like (5) "I exist" - would thereby express an a priori truth. The reason is that the contingent truth $\mathrm{S}$ would thereby say cannot be self-evident to anyone else. There is no sentence such that were someone else to utter that sentence they would say what S says by uttering "I exist" and what they would say would (by D3) be self-evident to them. And there seems to be no other way that anyone else could know that truth a priori, that is, for others there is no way of knowing it of which it would be plausible to say that it is an a priori way of knowing it. And indeed there is no sentence such that were $\mathrm{S}$ herself to utter it tomorrow she would say what she says today by uttering "I exist" and what S would say by that utterance tomorrow would be self-evident to her. There seems to be no a priori way in which S could at some time other than now know the truth she would now express by uttering "I exist". I think we should not want to classify as a priori any truth that can be known a priori only to one person at one time, the person and time the truth is about. I can know 
a priori that I exist (now) and each of you can know a priori that you exist (now), but none of these truths is an a priori truth.

So, although

(T1) every a priori truth must be knowable a priori,

we cannot assert the converse, that every truth knowable a priori is a priori. The most we might venture to claim, I think, is that

(T2) any truth knowable a priori that is not deeply contingent is an a priori truth.

Or, perhaps equivalently, that

(T3) any truth that is in principle knowable a priori by anyone at any time is an a priori truth.

Does this hold? Consider the following sentence:

(7) There exists now at least one person.

This sentence satisfies the condition in (D3): if anyone were to utter this sentence and fully understood what she would thereby say, then it follows that she would believe what she would thereby say, and so what she would say would be self-evident to her. It also follows that what she would thereby say is true and therefore something that she (then) knows a priori. But what she would say would be deeply contingent. Moreover, unlike the case with sentence (5), what she would say would be the same thing as anyone else would say by uttering sentence (7). So we have a deeply contingent, and therefore not a priori, truth that is knowable a priori by anyone. Do we therefore have a counterexample to (T3)? No we do not. Owing to the presence of the indexical "now", the truth expressed by the utterance of sentence (6) at any particular time is not knowable a priori (by anyone) at any other time.

What about the following sentence?

(8) There exists now, or has existed, or will exist at least one person.

The same is true of it: owing to the presence of the indexical "now", the truth expressed by the utterance of (8) at any particular time is not knowable a priori (by anyone) at any other time. It is true that utterances of sentence (8) at two different times say two things that are metaphysically equivalent, that is, it is metaphysically necessary that if either of them is true then so is the other. But the truth expressed by the one utterance is not the very same truth as the one expressed by the other utterance. The particular time referred to in the one utterance (by "now") is different from the particular time referred to in the other: In a 
loose sense they say the same thing, but they say it about two different particular times. So in a strict sense they do not say the same thing.

If sentence (8) does not provide a counterexample to (T3) then, I conjecture, no sentence will do so. I also see no reason not to accept the converse of (T3), namely, the claim that

(T4) Any a priori truth is one that is in principle knowable a priori by anyone at any time.

So I hazard the following claim about the relation between a priori truth and a priori knowability:

(T5) A truth is a priori if and only if it is in principle knowable a priori by anyone at any time. ${ }^{14}$

\section{References}

DEVITT, M. "Naturalism and the a priori". Philosophical Studies, 92 (1998), p. $45-65$.

DEVITT, M. "There is no a priori". In: Contemporary debates in epistemology. STEUP, M.; SOSA, E. (ed.). Blackwell Publishing, 2005, p. 105-114, 118-119.

EVANS, G. "Reference and contingency". The Monist, 62 (1979), p. 161-189.

GOLDMAN, A. "What is justified belief?" In: PAPPAS, G. (ed.). Justification and Knowledge. Dordrecht: Reidel, 1979, p. 1-23.

HARMAN, G. "The future of the a priori". In: ALTERMAN, R.; KIRSH, D. (ed.). Journal of Philosophical Research. Philosophy in America at the Turn of the Century, APA Centennial Supplement. Boston: Cognitive Science Society, 2003.

KELLEY, J. L. General topology. Princeton, 1955.

KITCHER, p. "Apriority and necessity". Australasian Journal of Philosophy, 58 (1980), p. 89-101.

PEACOCKE, C. How are a priori truths possible? European Journal of Philosophy, 1 (1993), p. 175-199.

PEACOCKE, C. "Implicit conceptions, the a priori, and the identity of concepts". Concepts (E. Villanueva. Atascadero, CA, Ridgeview), 9 (1998), p. 121-148.

PRYOR, J. "Hyper-reliability and apriority". Proceedings of the Aristotelian Society, 106 (2006), p. 327-344.

QUINE, W. V.; ULLIAN, J.S. The web of belief. Random House, 1970.

${ }^{14}$ I am grateful for helpful comments I received when I presented earlier versions of this paper to the Epistemology and Metaphysics Discussion Group at the University of Toronto, to the Conference on the Epistemology of Keith Lehrer at the PUCRS, Porto Alegre, Brazil, and to the Philosophy Department at the University of Sussex. 